\title{
Correlation of Lipid Profile \& Acute Inflammatory Markers in Rheumatoid Arthritis
}

\author{
Anand Jain ${ }^{1}$, Vishvanayak', Bajrang Lal ${ }^{3}$, V. K. Singh ${ }^{4}$, Najmul Hudda $^{5}$, S. Asif Rafiq ${ }^{6}$ \\ ${ }^{1}$ Postgraduate Student, Department of Medicine, TMMC \& RC, ${ }^{2}$ Professor, Department of Medicine, TMMC \& RC, ${ }^{3}$ Associate Professor, Department of \\ Medicine, TMMC \& RC, ${ }^{4}$ Professor, Department of Medicine, TMMC\&RC, ${ }^{5}$ Professor, Department of Medicine, TMMC \& RC, ${ }^{6}$ Senior Resident, \\ Gestroentrologist, Super specialty Hospital JMC, Shrinagar.
}

\section{Abstract}

Background: Rheumatoid arthritis (RA) primarily affect the synovium and is a chronic inflammation disease, which leads to joint damage and bone destruction. Causes of significant morbidity are due to result of synovial inflammation, joint destruction and associated disability. Many pieces of evidence suggest that proatherogenic disease associated with increased cardiovascular (CV) mortality is rheumatoid arthritis (RA). Addition to genetic and conventional CV risk factors, chronic inflammation has emerged as a key component of this process. Cardiovascular concerned demises shown a preferment in CRP among RA cases who have ongoing active inflammation that's why CRP can be self-sufficient pointer for cardiovascular disease. Subjects and Methods: Current study has been conducted in Teerthanker Mahaveer hospital, Teerthanker Mahaveer medical college. Data has been collected in duration of 12 months. After obtaining consent, data has been collected from 60 consecutive established case of rheumatoid arthritis. Almost equal number of participants were belonging to 30-39 years (16, 26.7\%), 40-49 years $(15,25.0 \%)$, and 50-59 years $(16,26.7 \%)$ age groups. Very few participants were belonging to 20-29 years $(4,6.7 \%)$ and $60-69$ years $(9$, 15.0\%). Range of age was from 25 years to 69 years. Results: Pearson correlation coefficient of CPR with Total cholesterol, HDL-C, Triglyceride, LDL-C and VLDL-C were $-0.326,-0.269,-0.307,-0.310$ and -0.307 respectively. All the correlation coefficients were statistically significant $(<0.05)$. Correlation coefficient of ESR with Total cholesterol, HDL-C, Triglyceride, LDL-C and VLDLC were -0.294 , $-0.311,-0.226,-0.253$ and -0.226 respectively. Among them correlation coefficient of ESR with total cholesterol (p-value=0.023) and HDL-C (p-value $=0.016)$ were statistically significant $(<0.05)$. Conclusion: General population danger of atherosclerosis surmount with increment in LDL and wane of HDL but in RA population there is wear off in HDL LDL and total cholesterol, when present in its inflammatory condition. There is a difference in the lipid trend in RA patient then the general population. Rheumatoid arthritis is a disease with lipid paradox. A high inflammatory burden determined by the mean values of ESR and CRP in active disease is associated with low lipid levels but more risk of CV events.

Keywords: LDL, HTL, ESR, CRP, RA.

Corresponding Author: Dr. Vishvanayak, Professor, Department of Medicine, TMMC\&RC.

Received: December 2019

Accepted: December 2019

\section{Introduction}

Rheumatoid arthritis (RA) primarily affect the synovium and is a chronic inflammation disease, which leads to joint damage and bone destruction. ${ }^{1]}$ Causes of significant morbidity are due to result of synovial inflammation, joint destruction and associated disability. ${ }^{[2]}$ Several Epidemiological data have shown an enhancement in premature demises in patients of RA then the general population. RA, a chronic inflammatory disease of, etiology being unknown RA is noticeable by a symmetric, peripheral polyarthritis. Most hackneyed form of long standing inflammatory arthritis is RA and every so often results in joint damage causing physical disability. Other than articular manifestation, it can lead to fatigue, subcutaneous nodules, lung involvement, pericarditis, peripheral neuropathy, vasculitis, and hematologic abnormalities. ${ }^{[3-7]}$ Its occurrence is around 1 percent, and has a female predisposition twice more than that in men. ${ }^{[8-10]}$

RA is gentle in onset over weeks to months in $55 \%$ to $65 \%$ of cases. ${ }^{[11]}$ The preliminary symptoms probably systemic or articular. Other symptoms include fatigue, malaise, swollen hands, and diffuse musculoskeletal pain which can be the prime nonspecific complaints, joints are involved later in the disease $s$ it progresses. A focused attention is required in periarticular structure if the tendon sheath are involved early in the process. Initial presentations are asymmetric and it is common than the symmetric presentation. Symmetric presentation is seen in late stage of disease. The cause of symmetry is still unknown. $8 \%$ to 15 percent of the patient can have an acute presentation of disease with peak within a few days. Before making a diagnosis of acute onset of RA, sepsis and vasculitis should be rule out. One prominent sign of sepsis is fever. If the symptoms develop over days to week, a diagnosis of intermediate type of onset can be made, occurring in $15-20$ percent of patient. In intermediate type onset systemic complaint are more noticeable than in 
insidious. ${ }^{[12]}$ Patients with a typical initiation of gradual discomfort, morning stiffness and symmetric inflammation of tiny joints are just one of the trends with no visible symptoms of swelling or proof of joint degradation on radiological investigation.

Acute onset found in one third patients and characterized by fatigue, weightloss, myalgias, malaise and morning stiffness and joint pain without any inflammation and radiological sign of joint erosion.

Traditionally RA affect the small joint of hands, wrist and feet. Sparing interphalangeal joints. Waiting for symmetry to initiate the therapy is not advisable as it occur late in the disease process. $30-40$ percent patients present with bilateral arthropathy of the shoulder and wrist.

Patient presenting with the involvement of knee is less than 5 $\%$. RA can involve any joint but hands, wrist, elbow, shoulder and knee are involved most commonly followed by hip joint and temporomandibular joint. It also affects the clavicular and cricoarytenoid joint.

Among the known complication of RA atlantoaxial subluxation is a dreaded one and the patient may present with, pain radiating toward the occiput, spastic quadriparesis or sensory finding. These patient belong to high risk of progression and immediate surgical stabilization is required in patients with evidence of cord compression.

Tenosynovitis /bursitis can also be presenting feature. Which can cause "trigger" finger. "Swan neck" and "boutonniere" deformity is the classical deformity but appear late in disease and are hallmark features of chronic illness.

In the initial presentation sign of synovitis and joint damage are usually subtle. There is no evidence of stress either physical or physiological being a risk factor to trigger for a disease. Following cardiac disease, it is the second most common cause of death. Most specifically, patients with RA are more vulnerable to septic arthritis, frequently worsened by the use of immunosuppressive drugs, including steroids. The normal symptoms of sepsis may be missing in such a case, preventing the diagnosis. Felty's syndrome

In this there is splenomegaly and neutropenia are linked with seropositive RA. Often common hepatomegaly and lymphadenopathy in RA. There is increasing evidence that people with RA, irrespective of typical risk factors, are suffering from elevated cardiovascular disease. Many pieces of evidence suggest that proatherogenic disease associated with increased cardiovascular (CV) mortality is rheumatoid arthritis (RA). ${ }^{[13,14]}$ In addition to genetic and conventional $\mathrm{CV}$ risk factors, chronic inflammation has emerged as a key component of this process. ${ }^{[15,16]}$

CRP, which is offered by the hepatocytes cell of liver under the impact of IL6 and TNF that's why taken as indirect indicator of inflammation. This marker is allied with plaque building in vessel. Which further surmount the danger of cardiovascular phenomena. ${ }^{[17-19]}$ This is also seen in various cohort study that cardiovascular concerned demises shown a preferment in CRP among RA cases who have ongoing active inflammation that's why CRP can be self-sufficient pointer for cardiovascular disease 28 In general population danger of atherosclerosis surmount with increment in LDL and wane of HDL, but in RA population there is wear off in
HDL LDL and total cholesterol, when present in its inflammatory condition. ${ }^{[20,21]}$ After giving treatment in these patient there is Surmount in total cholesterol HDL LDL and the interesting thing is that this surmount values are not related with danger of cardiovascular event. ${ }^{[21,22]}$

Inflammation is believed to play an important role in the progression of atherosclerosis, and it may be clarified by the systemic inflammatory response in RA. Data suggest that coronary mortality rises in early or advanced disease patients and is worse in women, a group that is generally at lower risk. Standardized cardiovascular disease death rates for people are about 1.3 and 1.9 for females.

Aim and objective: To study the lipid profile in patients of established rheumatoid arthritis. To study the association of lipid profile with inflammatory markers: "ESR (Erythrocyte sedimentation rate) and CRP (C eactive protein)."

\section{Subjects and Methods}

\section{Study place}

- The study will be conducted in the Teerthanker Mahaveer Medical College \& Research Centre, Moradabad (Uttar Pradesh). Data taken from the patients attending both OPD and IPD.

Study Duration

- Study will be done for 12 months. After taking approval from ethical and research committee.

Sample method and sample size

- On the next visit of established rheumatoid arthritis patients in OPD; or IPD, blood samples will be taken and the level of different lipid components, ESR and CRP will be detected.

- All Cases will be selected for prospective study.

- In all instances, the test is latex fixation, check for rheumatoid factor was conducted.

- The blood samples were obtained from RA patients after 12 hours of overnight fasting, regular diet (without any fat restriction) for the previous two weeks, and abstinence from alcohol. Serum was separated from the blood and stored in the fridge. This was then used in analytical studies of lipoprotein.

- With commercially available reagents, the concentration of total cholesterol, HDL-cholesterol, and triglycerides was evaluated enzymatically.

- LDL-cholesterol concentration was calculated using the Fried Ewald equation for participants with triglycerides (< $400 \mathrm{mg} / \mathrm{dl}$ ) LDL = TC = HDL-c = TGL/5.

- Inflammation marker such as ESR has been measured using Wintrobe's method.

Selection of Patients is on the basis of following Inclusion \& Exclusion Criteria

\section{Inclusion criteria}

- Diagnosed Patients of rheumatoid arthritis of either sex above the age of 18 years with disease duration of $>6$ months.

Exclusion criteria:

- Smokers 
- Diabetes mellitus

- Hypothyroidism

- Liver or kidney disease

- Obesity (body mass index $>/=25$ )

- Patients receiving medications affecting lipid metabolism, such as lipid-lowering drugs, beta-blockers, oral contraceptives, estrogen, progestin, thyroxin and vitamin E, will be excluded from the study.

\section{Statistical Analysis}

It was carried out for 60 patients of established cases of rheumatoid arthritis. Base line data was collected from patients (after taking consent) age, sex, duration of illness, lipid profile, ESR and CRP were analyzed.

The correlation amid in lipid profile and ESR \& CRP with the vindication of Pearson's correlation coefficient method. Statistical significance was taken when $\mathrm{p}$ value $<0.05$. Statistical analysis was carried out using standard formulae. Microsoft excel and SPSS (statistical package for social science) was used for data entry and analysis.

\section{Results}

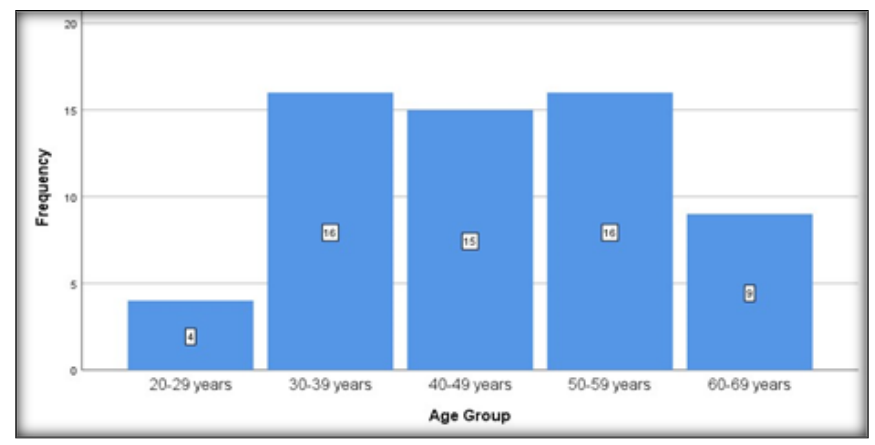

Figure 1: Age distribution of the participants

Table 1: Descriptive statistics of lipid profile parameter Total number of observations $n=60$

\begin{tabular}{|l|l|l|l|l|}
\hline $\begin{array}{l}\text { Lipid profile } \\
\text { parameter }\end{array}$ & Minimum & Maximum & Mean & $\begin{array}{l}\text { Std. } \\
\text { Deviation }\end{array}$ \\
\hline $\begin{array}{l}\text { Total } \\
\text { Cholesterol } \\
(\mathrm{mg} / \mathrm{dl})\end{array}$ & 111.0 & 310.0 & 196.6 & 43.7 \\
\hline $\begin{array}{l}\text { HDL-C } \\
(\mathrm{mg} / \mathrm{dl})\end{array}$ & 26.0 & 61.0 & 41.6 & 7.5 \\
\hline $\begin{array}{l}\text { Triglyceride } \\
(\mathrm{mg} / \mathrm{dl})\end{array}$ & 70.0 & 465.0 & 222.2 & 96.4 \\
\hline $\begin{array}{l}\text { LDL-C } \\
(\mathrm{mg} / \mathrm{dl})\end{array}$ & 65.2 & 182.0 & 107.8 & 22.4 \\
\hline $\begin{array}{l}\text { VLDL-C } \\
(\mathrm{mg} / \mathrm{dl})\end{array}$ & 14.0 & 93.0 & 44.4 & 19.2 \\
\hline
\end{tabular}

Current study has been conducted in Teerthanker Mahaveer hospital, Teerthanker Mahaveer medical college. Data has been collected in duration of 12 months. After obtaining consent, data has been collected from 60 consecutive established case of rheumatoid arthritis.

Almost equal number of participants were belonging to 3039 years $(16,26.7 \%), 40-49$ years $(15,25.0 \%)$, and $50-59$ years $(16,26.7 \%)$ age groups. Very few participants were belonging to $20-29$ years $(4,6.7 \%)$ and $60-69$ years $(9$, $15.0 \%)$. Range of age was from 25 years to 69 years. [Table 1]
Most of the participants were female $(52,86.7 \%)$. Only few $(8,13.3 \%)$ were males.

Mean (SD) of Total cholesterol, HDL-C, Triglyceride, LDL$\mathrm{C}$ and VLDL were 196.6(43.7) $\mathrm{mg} / \mathrm{dl}, 41.6(7.5) \mathrm{mg} / \mathrm{dl}, 222.2$ (96.4) $\mathrm{mg} / \mathrm{dl}, 107.8(22.4) \mathrm{mg} / \mathrm{dl}$, and $44.4(19.2) \mathrm{mg} / \mathrm{dl}$ respectively. [Table 2]

Table 2: Descriptive statistics of acute phase reactants

\begin{tabular}{|l|l|l|l|l|}
\hline $\begin{array}{l}\text { ESR }(\mathrm{mm} \text { per } \\
\text { hour })\end{array}$ & 8.0 & 118.0 & 37.3 & 27.06174 \\
\hline $\mathrm{CRP}(\mathrm{mg} / \mathrm{dl})$ & 0.4 & 9.8 & 1.9650 & 2.04017 \\
\hline
\end{tabular}

Table 3: Correlation of CRP with Lipid Profile parameters

\begin{tabular}{|l|l|l|}
\hline \multirow{2}{*}{ Table 3: Correlation of CRP with Lipid Profile parameters } \\
\cline { 2 - 3 } & CRP & \\
\hline Total Cholesterol & $-0.326^{*}$ & P value \\
\hline HDL-C & $-0.269^{*}$ & 0.011 \\
\hline Triglyceride & $-0.307^{*}$ & 0.037 \\
\hline LDL-C & $-0.310^{*}$ & 0.017 \\
\hline VLDL-C & $-0.307^{*}$ & 0.016 \\
\hline
\end{tabular}

*Statistically significant $(\mathrm{p}$ value $<0.05)$

Pearson correlation coefficient of CPR with Total cholesterol, HDL-C, Triglyceride, LDL-C and VLDL-C were $-0.326,-0.269,-0.307,-0.310$ and -0.307 respectively. All the correlation coefficients were statistically significant $(<0.05)$.

Table 4: Correlation of ESR with Lipid Profile parameters

\begin{tabular}{|l|l|l|}
\hline \multirow{2}{*}{} & ESR & \\
\cline { 2 - 3 } & Pearson Correlation & P value \\
\hline Total Cholesterol & $-0.294^{*}$ & 0.023 \\
\hline HDL-C & $-0.311^{*}$ & 0.016 \\
\hline Triglyceride & -0.226 & 0.082 \\
\hline LDL-C & -0.253 & 0.051 \\
\hline VLDL-C & -0.226 & 0.082 \\
\hline
\end{tabular}

*Statistically significant $(\mathrm{p}$ value $<0.05)$

Correlation coefficient of ESR with Total cholesterol, HDLC, Triglyceride, LDL-C and VLDLC were $-0.294,-0.311$, $0.226,-0.253$ and -0.226 respectively. Among them correlation coefficient of ESR with total cholesterol (pvalue $=0.023)$ and HDL-C (p-value $=0.016)$ were statistically significant $(<0.05)$.

\section{Discussion}

RA is systemic inflammatory disease with increased risk of $\mathrm{CV}$ diseases. Active RA is a disease with high burden of inflammatory markers and associated with decreased Total cholesterol, LDL-cholesterol and HDL-cholesterol. ${ }^{[21]}$ current study has been conducted in Teerthanker Mahaveer Hospital, Teerthanker Mahaveer medical college. Data has been collected in duration of 12 months. After obtaining consent, data has been collected from 60 consecutive established case of rheumatoid arthritis.

In our study, almost equal number of participants were belong to $30-39$ years $(16,26.7 \%), 40-49$ years $(15,25.0 \%)$, and $50-59$ years $(16,26.7 \%)$ age groups. Very few participants were belong to $20-29$ years $(4,6.7 \%)$ and 60-69 years $(9,15.0 \%)$. Range of age was from 25 years to 69 
years. Mean age of participants was 47.05 years with standard deviation of 11.7 years. These finding are similar to previous studies conducted by Muzahim F et al, ${ }^{[23]}$ and Wan Heeyoo et al. ${ }^{[24]}$

In our study, we found that mean (SD) of Total cholesterol, HDL-C, Triglyceride, LDL-C and VLDL were 196.6(43.7) $\mathrm{mg} / \mathrm{dl}, \quad 41.6(7.5) \mathrm{mg} / \mathrm{dl}, \quad 222.2(96.4) \mathrm{mg} / \mathrm{dl}, \quad 107.8(22.4)$ $\mathrm{mg} / \mathrm{dl}$, and 44.4(19.2) $\mathrm{mg} / \mathrm{dlrespectively.} \mathrm{Total} \mathrm{cholesterol}$ values of our study (mean 196.6, SD $43.7 \mathrm{mg} / \mathrm{dl}$ ) are in accordance with previous research conducted by Svenson KL et al, ${ }^{[25]}$ Rantapaa-DahlqvistS et al, ${ }^{[26]}$ and Lazarevic $\mathrm{MB}$ et al. ${ }^{[27]}$ Mean HDL-C of our study (mean 41.6, SD $7.5 \mathrm{mg} / \mathrm{dl}$ ) is also similar to studies conducted by Curtis et al, ${ }^{[28]}$ Dursunoglu $\mathrm{D}$ et $a{ }^{[29]}$ and chen et al. ${ }^{[30]}$ Values obtained for Triglyceride (mean 222.2, SD $96.4 \mathrm{mg} / \mathrm{dl}$ ) are in the direction of other studies conducted by Vinapamula K S et al, ${ }^{[31]}$ and Curtis et al. ${ }^{[28]}$ It was also observed that values of LDL-C (mean 107.8, SD $22.4 \mathrm{mg} / \mathrm{dl}$ ) found in our study is in accordance to Dursunoglu D et al, ${ }^{[29]}$ and Curtis et al. ${ }^{[28]}$ Mean VLDL values in our studies were $44.4 \mathrm{mg} / \mathrm{dl}$ (with SD $19.2 \mathrm{mg} / \mathrm{dl})$.

In this research, Mean (SD) of ESR was 37.3 (SD 27.0) mm in 1st hour, which is in accordance with previous researches conducted by Der yuanchen et al, ${ }^{[30]}$ and Muzahim et al, ${ }^{[23]}$ In our study, Mean (SD) CRP was 1.9 (SD 2.0) $\mathrm{mg} / \mathrm{dl}$. The inflammatory markers (CRP/ESR) are high in active disease and low in inactive disease. In current study, Mean Total cholesterol, LDL-cholesterol and Triglycerides were found to be increased, but HDL-cholesterol was decreased.

In this research, Pearson correlation coefficient of CPR with Total cholesterol, HDL-C, Triglyceride, LDL-C and VLDL$\mathrm{C}$ were $-0.326,-0.269,-0.307,-0.310$ and -0.307 respectively. All the correlation coefficients were statistically significant $(<0.05)$. Similar observations (Negatively correlated CPR and Lipid profile parameters) were also noted by Douglas et al, ${ }^{[32]}$ Robertson J et al, ${ }^{[21]}$ Athanasios et al, ${ }^{[33]}$ and Hyon K Choi et al. ${ }^{[34]}$

In current study, Correlation coefficient of ESR with Total cholesterol, HDL-C, Triglyceride, LDL-C and VLDL-C were $-0.294,-0.311,-0.226,-0.253$ and -0.226 respectively. Among them correlation coefficient of ESR with total cholesterol ( $\mathrm{p}$-value $=0.023$ ) and HDL-C (pvalue $=0.016$ ) were statistically significant $(<0.05)$. These findings are in accordance with studies conducted by Douglas et al, ${ }^{[32]}$ and Athanasios et al. ${ }^{[33]}$

In general population danger of atherosclerosis surmount with increment in LDL and wane of HDL but in RA population there is wear off in HDL LDL and total cholesterol, when present in its inflammatory condition. There is a difference in the lipid trend in RA patient then the general population. Rheumatoid arthritis is a disease with lipid paradox. A high inflammatory burden determined by the mean values of ESR and CRP in active disease is associated with low lipid levels but more risk of CV events. There is oxidative modification in LDL morphology and along with this decrement in the apolipoprotein A1 values. Paraoxnase- one is an enzyme with antioxidant antiinflammatory and antiatherogenic activity, there is reduction in this activity of paraoxnase led atheroma formation.

\section{Conclusion}

A better grip on the activity of RA lesser chances of cardiovascular event in these patients. Use of statin in RA is considerable in atherosclerotic cardiovascular disease. Norwegian researcher sem at al tell from his perusal tell that statin lead to wane in lipid value and $20 \%$ decrement in the total cardiovascular risk in active disease with respect to inactive RA. Rollefstad et al also value the use of statin. Mc Carey et al appraise statin (atorvastatin) role in disease activity through this he rooted moderate decrease in disease activity and reformation in lipid. So regardless of lipid value statin have to be considered in RA.

\section{References}

1. Gravallese EM. Bone destruction in arthritis. Ann Rheum Dis 2002; 61 (Suppl 2) : ii84-ii86.

2. Gabriel SE, Crowson CS, Kremers HM, Doran MF, Turesson C, O'Fallen WM, Matteson EL. Survival in rheumatoid arthritis: a population-based analysis of trends over 40 years. Arthritis Rheum: 2003; 48: 54-58.

3. Isomaki HA, Mutru O, Koota K. Death rate and causes of death in patients with rheumatoid arthritis. Scand J Rheumatol 1975; 4: 205-208.

4. Mutru O, Laakso M, Isomaki $\mathrm{H}$, Koota $\mathrm{K}$. Ten year mortality and causes of death in patients with rheumatoid arthritis. Br Med J (Clin Res Ed) 1985; 290: 1797-1799.

5. Watson DJ, Rhodes T, Guess HA. All-cause mortality and vascular events among patients with rheumatoid arthritis, osteoarthritis, or no arthritis in the UK General Practice Research Database. J Rheumatol: 2003; 30: 1196-1202.

6. Pinals RS. Survival in rheumatoid arthritis. Arthritis Rheum 1987; 30: 473-475.

7. Mitchell DM, Spitz PW, Young DY, Bloch DA, McShane DJ, Fries JF. Survival, prognosis, and causes of death in rheumatoid arthritis. Arthritis Rheum 1986; 29: 706-714.

8. Wolfe A.M. The epidemiology of rheumatoid arthritis: A review, I: Surveys. Bull Rheum Dis 1968; 19: 518-523.

9. Engel A., Roberts J., Burch T.A. Rheumatoid arthritis in adults in the United States, 1960-1962. In Vital and Health Statistics, Series 11, Data from the National Health Survey, Number 17. Washington, DC, National Center for Health Statistics, 1966.

10. Mikkelsen W.M., Dodge H.J., Duff I.F., et al. Estimates of the prevalence of rheumatic disease in the population of Tecumseh, Michigan, 1959-1960. J Chronic Dis 1967; 20: 351-369.

11. Fleming A., Crown J.M., Corbett M.: Early rheumatoid disease, I: Onset. Ann Rheum Dis 1976; 35: 357-360.

12. Joshi VR. Rheumatology, Past, Present and Future. JAPI. 2012;60:2124.

13. Gonzalez-Gay MA, Gonzalez-Juanatey C, Martin J. Rheumatoid arthritis: a disease associated with accelerated atherogenesis. Semin Arthritis Rheum 2005;35:8-17.

14. Aviña-Zubieta JA, Choi HK, Sadatsafavi $M$, et al. Risk of cardiovascular mortality in patients with rheumatoid arthritis: a metaanalysis of observational studies. Arthritis Rheum 2008;59:1690-7.

15. Dessein PH, Joffe BI, Veller MG, et al. Traditional and nontraditional cardiovascular risk factors are associated with atherosclerosis in rheumatoid arthritis. J Rheumatol 2005;32:435-42.

16. López-Mejías R, García-Bermúdez M, González-Juanatey $\mathrm{C}$, et al. NFKB1-94ATTG ins/del polymorphism (rs28362491) is associated with cardiovascular disease in patients with rheumatoid arthritis. Atherosclerosis 2012;224:426-9.

17. Gonzalez-Gay MA, Gonzalez-Juanatey C, Piñeiro A, et al. Highgrade C-reactive protein elevation correlates with accelerated atherogenesis in patients with rheumatoid arthritis. J Rheumatol2005;32:1219-23.

18. Gonzalez-Gay MA, Gonzalez-Juanatey C, Lopez- Diaz MJ, et al. HLADRB1 and persistent chronic in flammation contribute to cardiovascular events and cardiovascular mortality in patients with rheumatoid arthritis. Arthritis Rheum 2007;57:125-32. 
19. Myasoedova E, Crowson CS, Kremers HM, et al. Lipid paradox in rheumatoid arthritis: the impact of serum lipid measures and systemic in- flammation on the risk of cardiovascular disease. Ann Rheum Dis 2011;70:482-7.

20. Perk J, De Backer G, Gohlke H, et al. European Guidelines on cardiovascular disease prevention in clinical practice (version 2012). The Fifth Joint Task Force of the European Society of Cardiology and Other Societies on Cardiovascular Disease Prevention in Clinical Practice (constituted by representatives of nine societies and by invited experts) .Eur Heart J 2012;33:1635-701.

21. Robertson J, Peters MJ, McInnes IB, et al. Changes in lipid levels with inflammation and therapy in RA: a maturing paradigm. Nat Rev Rheumatol 2013;9:513-23.

22. Van Sijl AM, Peters MJ, Knol DL, et al. The effect of TNF-alpha blocking therapy on lipid levels in rheumatoid arthritis: a metaanalysis. Semin Arthritis Rheum 2011;41:393-400.

23. Muzahim F. AL-Chetachi, Yousef A. Shaher. Lipid status in rheumatoid arthritis, University of Mosul Page 118-124

24. Wan-HeeYooDyslipoproteinemia in patients with active rheumatoid arthritis: effects of disease activity, sex, and menopausal status on lipid profiles The Journal of Rheumatology vol.31 no.9 1746-1753

25. Svenson KL, Lithell H, Hallgren R, Selinus I, Vessby B. Serum lipoprotein in active rheumatoid arthritis and other chronic inflammatory arthritides. I. Relativity to inflammatory activity. Arch Intern Med 1987; 147:1912-6.

26. Rantapaa-Dahlqvist S, Wallberg-Jonsson S, Dahlen G. Lipoprotein (a), lip- ids and lipoproteins in patients with rheumatoid arthritis. Ann Rheum Dis 1991; 50:366-8.

27. Lazarevic MB, Vitic J, Mladenovic V, Myones BL, Skosey JL, Swedler
WI. Dyslipoproteinemia in the course of active rheumatoid arthritis. Seminars in Arthritis and Rheumatism 1992; 22:172-8.

28. Jeffrey R. Curtis, Onur Baser Dyslipidemia and changes in lipid profiles associated with rheumatoid arthritis and initiation of anti-TNF therapy; Arthritis Care Res (Hoboken), 2012 September ;64 (9):1282-1291. doi:10.1002/acr.21693

29. Dursunoglu D, Evrengul H, Polat B, et al. Lp (a) lipoprotein and lipids in patients with rheumatoid arthritis: serum levels and relationship to inflammation. Rheumatol Int. 2005; 25:241-5.

30. Chen et al. Arthritis Research and Therapy (2015) . Significant effects of biologic therapy on lipid profiles and insulin resistance in patients with rheumatoid arthritis.DOI 10.1186/s 13075-015-0558-8

31. Kiranmayi S. Vinapamula, Suchitra M. Manohar, Aparna R. Bitla, RajyalakshmiKanduri, Siddartha Kumar Bhattaram, Srinivasa Rao V.L.N. Pemmaraju Evaluation of Dyslipidemia in patients with rheumatoid arthritis in South Indian population Indian Journal of Rheumatology Volume 8, Issue 4, December 2013, Pages 155-160

32. Douglas White, Sayed Fayez, Alan Doube. Atherogenic lipid profiles in rheumatoid arthritis. Journal of the New Zealand Medical Association Aug. 2006; Vol. 119, No. 1240.

33. Athanasios N Georgiadis, Eleni C Papavasiliou et al Atherogenic lipid profile is a characteristic of patients with early rheumatoid arthritis:Effect of early treatment- A prospective study; Arthritis Res Ther. 2006;8 (3): R82 Published online 2006 Apr 28.

34. Hyon K Choi and John D Seeger. Lipid profiles among US elderly with untreated rheumatoid arthritis--the Third National Health and Nutrition Examination Survey. The Journal of Rheumatology: 2005; 32 no. 12 2311-2316

Copyright: (C) the author(s), 2019. It is an open-access article distributed under the terms of the Creative Commons Attribution License (CC BY 4.0), which permits authors to retain ownership of the copyright for their content, and allow anyone to download, reuse, reprint, modify, distribute and/or copy the content as long as the original authors and source are cited.

How to cite this article: Jain A, Vishvanayak, Lal B, Singh VK, Hudda N, Asif Rafiq SA. Correlation of Lipid Profile \& Acute Inflammatory Markers in Rheumatoid Arthritis.Acad. J Med. 2019;2(2):190-94.

DOI: dx.doi.org/10.21276/ajm.2019.2.2.49

Source of Support: Nil, Conflict of Interest: None declared. 